DERLEME / REVIEW

\title{
Epilepside Tedavi Stratejileri
}

\author{
Epilepsy Treatment Strategies \\ Zekiye TOKLU' \\ ${ }^{1}$ Afyonkarahisar Devlet Hastanesi, Nöroloji Kliniği, Afyonkarahisar \\ Geliş Tarihi / Received: 22.05.2012 \\ Kabul Tarihi / Accepted: 28.05.2012
}

\begin{abstract}
ÖZET
Epilepsi tedavisini planlarken nöbetin tipi, epilepsi sendromu, nöbetlerin beklenen doğal seyri ve rekürrens riskinin belirlenebilmesi birincil önem taşımaktadır. Bunun yanında hastanın olası tutum ve davranışları, yaşam koşulları, psikososyal durumu ve en önemlisi tedaviden beklentileri de dikkate alınmalıdır. Epilepside tekrarlayan nöbetlerin olumsuz sonuçlarına karşılık, antiepileptik ilaçların yarar/zarar oranı hesaba katılmalıdır. Genel yaklaşım ikinci nöbetten sonra tedavi başlanması yönündedeir. Mümkünse monoterapi tercih edilmeli ve eğer ilk ilaç etkili olmazsa ikinci monoterapi ve/veya politerapi uygulanabilir. Epilepsi tedavisinde hedef, herhangi bir yan etkiye yol açmadan, nöbetlerin tamamen önlenebilmesidir.
\end{abstract}

Anahtar Kelimeler: Epilepsi tedavisi, nöbet tipi, monoterapi.

\section{ABSTRACT}

When planning the treatment of epilepsy, determination of seizure type, epilepsy syndrome, expected natural course and recurrence risk of seizures, is primary importance. In addition, the possible attitudes and behaviors of the patient, his/her living conditions, psychosocial status, and most importantly, expectations from the treatment should be considered. In response to the negative consequences of recurrent seizures in epilepsy, the risk/benefit ratio of antiepiletic drugs should be considered. The general approach is to start to the treatment after second seizure. And, if possible, monotherapy should be preferred and if the first drug is not effective, second monotherapy and/or polytherapy might be applied. The aim of the treatment of epilepsy is to prevent completely the seizures without and side effects.

Keywords: The treatment of epilepsy, seizure type, monoterapy. 


\section{Gíriş}

Epilepsi hemen her yaşta görülebilen ve uzun süreli tedavi ve izleme gerektiren bir hastalık olup yaşam kalitesini önemli ölçüde etkiler (1). Epilepsi tedavisinde ilk basamak tanının doğru konması ve ilaçla tedaviye gerek olup olmadığının belirlenmesidir (2). Epilepsi tanısı alan bir kişide antiepileptik ilaç (AEI) tedavisine başlama kararı verirken nöbet tipi, epilepsi sendromu, söz konusu epilepsideki nöbetlerin beklenen doğal seyri ve rekürrens riskinin belirlenebilmesi birincil önem taşımaktadır (3).

\section{TEDAVI STRATEJILERi}

Epilepsi tedavisinin üç hedefi vardır: Nöbetleri ortadan kaldırmak ya da sıklığı mümkün oldukça azaltmak, uzun dönemli tedaviyle iliş̧ili yan etkilerden kaçınmak ve hastanın normal psikososyal ve iş uyumunu koruması ya da yeniden sağlamasına yardım etmektir (4). Genel eğilim AEl tedavisinin ikinci nöbetten sonra başlanması yönündedir.

AEi'ların ilk nöbetten sonra başlanması aşağıdaki durumlarda düşünülmelidir (1):

$\begin{array}{ll}\text { - } & \text { Hastada nörolojik defisit varsa } \\ \text { - } \quad \text { Hasta ve/veya ailesi ikinci nöbet riskini } \\ \text { - } \quad \text { göze almayı kaldıramıorlarsa } \\ \text { MRI'da yapısal lezyon varsa }\end{array}$

Yeni tanı almış nöbetli bir hastanın profilaktik AEl tedavisine başlamadan önce nöbetlerin epileptik olduğundan emin olunmalıdır (5). İlk seçenek AEI optimal dozlarda kullanılırken nöbetler devam ediyorsa epilepsi tanısı ciddi olarak gözden geçirilmelidir. Mümkünse monoterapi tercih edilmeli ve eğer ilk ilaç etkili olmazsa ikinci monoterapi uygulanabilir (1). Epilepsi tanısı almış hastaların yaklaşık \%70'inde kullandıkları AEl ile nöbetlerin tamamı veya hemen hemen tama yakını kontrol altına alınır. \%20 ile $\% 25$ 'inde ise nöbetlerin sayısı ve şiddeti belirgin azalır (6).

Tedavide seçilecek AEl etkili ve aynı zamanda uzun süreli koruyucu olmalı, iyi tolere edilebilmeli, ilaç etkileşimi olmamalı ya da düşük olmalı, yaşam kalitesini artırmalıdır. Monoterapi tercih edilirken, "yeni" (ikinci jenerasyon) AEI'lerin de geleneksel (konvansiyonel) AEl'ler kadar etkili olabileceği unutulmamalıdır. Amerikan Nöroloji Akademisi'nin tedavi protokolünde yeni AEI'lardan lamotrijin, okskarbazepin, topiramat ve gabapentin başlangıç monoterapisinde önerilmektedir. Burada levetirasetam (LEV) ve pregabalin dahil edilmemiştir. Ancak geniş bir etki spektrumuna sahip olan LEV fokal (parsiyel) epilepsilerin çeşitli nöbet tiplerinde başlangıç monoterapisinde yaygın olarak kullanılmaktadır. Yeni tanı alan epilepsi hastalarında geleneksel AEl'lerden fenitoin, karbamazepin, valproat ve fenobarbitalin eşit etkilere sahip oldukları düşünülmesine karşın, örneğin barbitüratların nörotoksik ve kognitif yan etkilerinin daha fazla olduğu unutulmamalıdır. Geleneksel AEI'ler; daha ucuz olmaları, uzun süreli kullanım deneyimlerinin olması, yan etkilerinin daha çok bilinmeleri nedeni ile daha fazla tercih edilirler. Yeni AEl'lerin daha iyi tolere edildikleri, yan etkilerinin ve ilaç etkileşimlerinin daha az olduğu bilinmektedir (3). Epilepsinin çeşitli tiplerinde seçilecek ilaç seçimi için genel yaklaşım Tablo 1 'de belirtilmiştir (2).

Çocuk doğurma yaşındaki kadın hastada daha tedaviye başlarken bazı noktalar düşünülmelidir. Doğurganlık çağındaki kadınlar için, AEílar ile hormonal kontraseptif ilaçların ilaç etkileşimi düşünülmelidir (7). Enzim indüklemeyen AEI'lar (gabapentin, lamotrijin, levetirasetam, valproat sodyum), oral kontraseptiflerin etkinliğini değiştirmezler. Enzim indükleyici AEI (karbamazepin, etosüksimid, fenobarbital, fenitoin, primidon) kullanan kadın hastalarda oral kontraseptif ilk tercih edilen kontrasepsiyon yöntemi değildir. Bununla birlikte, kadın hasta oral kontraseptif kullanmayı istiyorsa, kontrasepsiyon etkinliğinin azalacağı bilgisi verilmelidir (1).

Gebelik sırasındaki epilepsi tedavisi, AEI'ların fetüs üzerine potansiyel yan etkileri ile nöbetlerin anne ve fetüs üzerinde neden olabilceği riskler göz önüne alınarak planlanmalıdır. Gebelik sırasında AEi'ların farmakokinetik özelliklerinde belirgin değiş̧iklik olabilir (8). Nöbetleri kontrol etmek için en uygun ve en düşük etkili dozda, AEİın kullanılması önerilmektedir (9). 
Tablo 1: Antiepileptik ilaçların etkili oldukları nöbet tipleri.

\begin{tabular}{|l|c|c|c|c|}
\hline İlaç & Fokal başlangıçlı nöbet & Primer jeneralize nöbet & Absans & Miyokloni \\
\hline Fenitoin & + & + & - & - \\
\hline Karbamazepin & + & + & - & - \\
\hline Lamotrijin & + & + & + & $+/-$ \\
\hline Zonisamid & + & + & $(+)$ & $(+)$ \\
\hline Fenobarbital ve Primidon & + & + & - & $+/-$ \\
\hline Benzodiazepin & + & + & + & $(+)$ \\
\hline Vigabatrin & + & + & - & - \\
\hline Tiagabin** & + & + & - & - \\
\hline Etosüksimid & - & - & + & \\
\hline Valproik asit & + & + & + & + \\
\hline Topiramat & + & + & $(+)$ & $(+)$ \\
\hline Gabapentin & + & + & - & - \\
\hline Pregabalin & + & + & - & - \\
\hline Levetirasetam & + & $(+)$ & $(+)$ & $(+)$ \\
\hline Felbama*** & + & + & $(+)$ & \\
\hline Okskarbazepin & + & + & - & - \\
\hline
\end{tabular}

Parentez içindekiler: Etkinliklerinin daha az olmasını gösteriyor; -: hiç etkisi yok veya nöbeti kötüleştirdiğini gösteriyor. **Ülkemizde bulunmamaktadır.

AEl'ların kemik metabolizmasını etkilemeleri sonucu menopoz döneminde osteoporoz riski artmaktadır. Fenitoin, karbamazepin, primidon ve fenobarbital gibi enzim indükleyen AEI kullanan hastalarda, vitamin $D$ düzeyi düşme eğilimlidir. Bu hastalarda serum paratiroid hormon düzeyleri yükselmekte ve idrarda kalsiyum atıIımı azalmaktadır. VPA alan olgularda da kemik mineral dansitesinde azalma (\%14) olduğu gösterilmiştir. Lamotrijin, topiramat, vigabatrin ve gabapentinin kemik mineral dansitesini değiştirmediği gösterilmiştir.

Yaşlı epileptiklerde ilaç düzenlemesi yaparken göz önünde bulundurulması gereken durumlar unutulmamalıdır. AEI seçerken yaşlııı veya diğer hastalıklar nedeni ile kullanılan ilaçların etkisiyle oluşabilen önemli famakokinetik değişiklikleri hesaplamak gerekir (5). Yaşlılarda farmakokinetik ve farmakodinamik sensivite değişken olduğundan spesifik AEl dozu belirlenemez. Bu nedenle ilk kural düşük dozda yavaş başlanması, ikinci kural ise monoterapi olmalıdır (1-3). Yeni AEI'ların ilaç-ilaç etileşimi düşük ve toksisitesi az olduğundan yaşlı epileptiklerde kullanımı daha avantajıjır (10).

Epilepsi cerrahisi adayında nöbet kontrolü için uygun AEl'lar (İki monoterapi veya kombine tedavi) yeterince denenmiş olmalıdır. Epilepsi cerrahisi ile amaç nöbetleri durdurmak ve yaşam kalitesini arttırmaktır. Her zaman için yarar/ zarar oranı göz önüne alınmalıdır. Epilepsi cerrahisi için ana sebepler aşağıda sıralanmıştır (3):

- Tekrarlayan nöbete bağlı travma

- $\quad$ Aura olmaması, nöbetin uzun süreli ol ması ve sık olması

- $\quad$ Postiktal dönemin uzun sürmesi

- Kognitif, psikolojik ve/veya sosyal olarak yaşam kalitesinin bozulması

Yüksek doz politerapi kullanımı, yan etkiler

Epilepsi hastalarında ani beklenmeyen ölüm ("sudden unexpected death in epilepsy"-SUDEP) riskinin artmasI Psikiyatrik olarak depresyon riskinin artması

Progresif anatomik ve fonksiyonel değişiklikler

Yaşam kalitesinin belirgin azalması ve buna bağlı iş kaybı, boşanma vb.

Vagal sinir stimülasyonu AEI tedavisine dirençli ve fokal nöbetleri olan erişkin ve 12 yaş üzeri ergenler için onaylanmış invazif, farmakolojik olmayan bir ek tedavidir. Vagal sinir stimülasyonunun endikasyonu, epilepsi konusunda 
spesifikleşmiş birimlerde nöroloji, noroşirurji, psikiyatri dallarından oluşan hekimlerin bulunduğu multidisipliner çalışma grubu tarafından değerlendirilmelidir.

Ketojenik diyet; erişkin epilepsili bireylerde önerilmemektedir. İlaca dirençli epilepsisi olan çocuklarda ek tedavi olarak ketojenik diyet önerilebilir (5-11).

Derin beyin stimülasyonu; Epilepside alternatif tedavi olarak denenmeye son yıllarda başlanmıştır. Mekanizması bilinmemektedir. En çok tercih edilen bölgeler talamusun anterior nukleusu, kaudat nukleus, talamusun santromedyan nukleusu, serebellum, hipokampus ve subtalamik nukleustur. Bu konuda yayınlanan çalışmalar çift kör olmadan yapılmış ve çok az sayıda hastadan oluşan serilerdir.

Antiepileptik ilaçların kronik kullanımında yan etkileri olabileceğinden ve bazı olgularda remisyonların görülmesi mümkün olduğundan çocukluk çağında son nöbetten 2 yıl, erişkinlikte ise 4-5 yıl sonra ilaç dozu yavaşça azalatılarak kesilebilir. Ancak burada da, tedaviye başlama konusunda olduğu gibi, öncelikle riskleri anlatarak hastanın görüşünü almak ve nöbetlerin sınıflanması rol oynar. En doğru yaklaşım genel ilaç kesim kriterleri yerine her hasta için özgün koşulları değerlendirerek hareket etmektir. İlaç kesimi sonrası ilk bir yıl içinde, özellikle ilk 3 ayda nöbet olma riskinin yüksek olduğu bilinmeli ve hiçbir zaman nöbet olma riskinin sıfır olmadığı hastaya anlatılmalıdır (12-13).

\section{KAYNAKLAR}

1. Nalan Kayrak, Çiğdem Özkara, Serap Saygı, Sibel Velioğlu. Epilepsi Rehberi, 2007:1

2. Baykan B, Gürses C, Gökyiğit A: Epilepsi. In: Öge A. E (edt). Nöroloji Ders Kitabı. İstanbul, Nobel Tıp Kitabevi, 2004:279-30

3. Prof. Dr. Murat Emre (edt). Nöroloji Temel Kitabı. Ankara: Güneş Tıp Kitabevleri, 2013:1073108
4. Merrit's Neurology. Lewis P. Rowland (edt). Çeviri Editörleri: Barış Baslo, Candan Gürses. İstanbul: Güneş Tıp Kitabevleri;2008:1000-14

5. C.P. Panayiotopoulos, Principles of Therapy in the Epilepsies. Epilepside Tedavi Prensipleri, Prof. Dr. Oğuz O. Erdinç (edt), Çeviri: Zeynep Beril Turgut. İstanbul: Nobel Tıp Kitabevleri, 2013:18

6. Allan H. Ropper, Robert H. Brown, Adams and Victor's Principles of Neurology. Çeviri Editörü: Murat Emre. İstanbul: Güneş Kitabevi, 2006:29299

7. Sudden Death in Epilepsy. Forensic and clinical issues Edited by Claire M. Lathers, Paul L. Schraeder, Michael W. Bungo, Jan E. Leestma. S. 764

8. Pharmacokinetic variability of newer antiepileptic drugs: when is monitoring needed? Johannessen SI, Tomson T. Clin Pharmaco Kinet 2006;45(11):1061-75

9. Guidelines fort he care of women of childbearing age with epilepsy. Epilepsia, 1993;34(4):588-589.

10. Choice and use of newer anticonvulsant drugs in older patients. Drugs Aging. 2000;17(6):441-52.

11. Richard S. McLachlan, MD. Vagus Nerve Stimulation for Treatment of Seizures? Arch Neurol, 1998;55(2):232-3.

12. Karceski S, Morrell MJ, Carpenter D. Treatment of epilepsy in adults: expert opinion. Epilepsy Behav. 2005 Sep; 7 Suppl 1:S1-64; quiz S65-7.

13. Bora I: Epilepsinin medikal tedavisi. In: Bora İ, Yeni N, Gürses C (edt). Epilepsi. İstanbul, Nobel Tıp Kitabevleri, 2008:595-607. 